Enlighten: Jurnal Bimbingan Konseling Islam

Volume 1 No 1 (Januari-Juni 2018) Hlm: 78 - 87

Tersedia online di http://journal.iainlangsa.ac.id/index.php/enlighten

ISSN 2622-8912

\title{
SELF REGULATED LEARNING MAHASISWA STKIP MUHAMMADIYAH SUNGAI PENUH
}

\author{
Ayu Permata Sari \\ Program Studi Bimbingan dan Konseling STKIP Muhammadiyah Sungai Penuh Jambi \\ E-mail: ayusoemantri@gmail.com
}

\begin{abstract}
Abstrak
Penelitian ini dilatar belakangi dari kegelisahan peneliti yang melihat masih rendahnya hasil belajar mahasiswa dan kurangnya kemandirian mahasiswa dalam belajar di STKIP Muhammadiyah sungai penuh. Oleh karena itu peneliti tertarik untuk meneliti tentang keadaan self regulated learning (SRL) mahasiswa STKIP Muhammadiyah sungai penuh dan menguji apakah terdapat perbedaan SRL pada mahasiswa laki-laki dan perempuan. Penelitian ini di menggunakan metode deskriptif dan deskriptif komparatif dengan populasi seluruh mahasiswa STKIP muhammadiyah sungai penuh TA 2017/2018 yang berjumlah 991 dengan sampel 276 melalui teknik sratified random sampling. Analisis data dengan menggunakan rumus presentasi dan T-test. Hasil penelitian menunjukan SRL mahasiswa tergolong menjadi 2 yaitu 32,5\% tergolong kurang baik dan 27,5\% tergolong baik. Uji hipotesis menunjukan adanya perbedaan signifikan antara SRL perempuan dan laki-laki dimana perempuan memiliki SRL lebih baik. Implikasi dari hasil penelitian ini dapat digunakan oleh orang tua dan pihak pengelola kampus dalam membuat progra peningkatan SRL mahasiswa agar mendapatkan hasil belajar yang lebih memuaskan.
\end{abstract}

Kata kunci: Self Regulated Learning, Laki-laki, Perempuan

\begin{abstract}
This research is based on the anxiety of researchers who see the low student learning outcomes and the lack of independence of students in learning at STKIP Muhammadiyah full river. Therefore, researchers are interested in examining the state of self regulated learning (SRL) students of the STKIP Muhammadiyah river full and testing whether there are differences in SRL for male and female students. This research uses descriptive and comparative descriptive method with the population of all STKIP Muhammadiyah Sungai FY students in 2017/2018 FY which totaled 991 with a sample of 276 through the sratified random sampling technique. Data analysis using the presentation formula and T-test. The results showed that student SRL was classified as 2, namely 32.5\% classified as poor and $27.5 \%$ classified as good. Hypothesis testing shows that there is a significant difference between female and male SRL where women have better SRL. The implications of the results of this study can be used by parents and campus administrators in making programs to improve student SRL to get more satisfying learning outcomes.
\end{abstract}

Keywords: Self Regulated Learning, Male, Female 


\section{PENDAHULUAN}

Perguruan tinggi yang menggunakan sistem kredit semester (SKS), Mahasiswa dituntut untuk memiliki kemandirian dalam belajar agar mendapatkan hasil belajar dan prestasi belajar yang baik. Menurut Prayitno, dkk (2002:10) dalam sistem kredit semester ini ada tiga bentuk kegiatan yang harus dilakukan mahasiswa yaitu, 1) mengikuti perkuliahan tatap muka terjadwal yang berlangsung 16-17 kali pertemuan dalam satu semester, 2) mengerjakan tugas-tugas yang diberikan oleh dosen, dan 3) kegiatan belajar mandiri. Kemandirian tersebut tentu lebih tinggi bila dibandingkan dengan siswa SMA.

Bila ditinjau dari usianya, mahasiswa pada tahun pertama memiliki usia sekitar 18-19 tahun. Pada usia ini, seorang manusia dianggap telah mampu untuk mengatur dirinya sendiri dalam hal belajar. Proses mengontrol diri sendiri dalam belajar dibut sebagai self regulated learning (SRL). Self regulated learning (SRL) merupakan suatu hal yang mempengaruhi prestasi belajar seorang mahasiswa. Hal ini sesuai dengan pernyataan Brown (dalam Paul, Elisabet, \& Robert, 1994:140) bahwa "Kontrol metakognitif dan SRL merupakan hal yang penting untuk mendapatkan hasil belajar yang optimal". Artinya disini bahwa mahasiswa atau pelajar yang lebih sadar dan mampu menerapkan kontrol yang lebih besar terhadap proses kognitifnya akan lebih sukses hasil belajar yang dimilikinya.

Pintrich (dalam schunk,2005) menyatakan bahwa SRL merupakan suatu proses yang dilakukan oleh seorang dimulai dari menetapkan tujuan yang akan dicapainya dalam belajar, kemudian mengusahakan pencapaian tujuan belajarnya tersebut dengan memonitor, mengatur, dan mengendalikan kognisi, motivasi dan prilakunya. Dari penjelasan tersebut dapat disimpulkan bahwa SRL ini menjadikan proses belajar pada siswa menjadi proses yang diarahkan dan diatur oleh dirinya sendiri bukan sekedar keinginan orang tua atau gurunya saja.

Kemudian dengan adanya SRL pada seseorang mahasiswa, akan menjadi lebih bertanggung jawab terhadap proses belajarnya, mahasiswa akan menkonstruksi sendiri konsep belajarnya dan solusi terhadap permasalahan belajarnya sendiri. Kemudian dengan SRL akan mampu mengembangkan tujuan utama dari pendidikan yaitu mengembangkan keterampilan belajar sepanjang hayat. 
Namun pada kenyataanya banyak mahasiswa yang tidak memilki SRL yang baik. Dapat dilihat bahwa banyak mahasiswa menunjukkan perilaku terlambat dating atau masuk ke kelas ketika perkuliahan, kadang dosen harus menunggu mahasiswanya datang sekitar 15 menit, kemudian banyak mahasiswa yang tidak menyelesaikan tugas-tugas sekolah, mencontek pada saat UTS dan UAS, kurang memanfaatkan fasilitas perpustakaan, nilai yang rendah dan rendahnya keinginan untuk meminta perbaikan nilai, tidak memiliki jadwal belajar rutin dan teratur, mengerjakan tugas matakuliah lain saat pelajaraan lainya sedang berlangsung dan belajar hanya malam hari ketika akan ujian dengan metode SKS (sistem kebut semalam).

Fenomena tersebut juga terjadi di kampus STKIP Muhammadiyah Sungai Penuh. Dari hasil observasi yang telah dilakukan selama lebih kurang satu semester yaitu pada semester genap 2016/2017 di prodi bimbingan dan konseling, mahasiswa masih sering terlambat masuk ke kelas, kadang dosen harus menunggu mahasiswanya datang karena kelas yang masih sepi dan terkadang mahasiswa yang ditugaskan untuk mempresentasikan bahan perkuliahan belum datang atau belum menyelesaikan bahan untuk dipresentasikan. Kemudian terdapat mahasiswa yang tidak membuat tugas mingguan yang diberikan oleh dosennya. Selain itu, kurangnya minat mahasiswa untuk memperbaiki nilai BL juga sering terjadi, mahasiswa yang mendapatkan nilai BL (belum lengkap) sangat jarang yang mengurus nilai tersebut dengan menemui dosen yang bersangkutan untuk mengetahui kelemahan pada dirinya. Kebanyakan mahasiswa akan membiarkan nilai BL tersebut, hal ini menunjukkan kurangnya kontrol diri mahasiswa dalam belajar.

Fenomena tersebut di dukung oleh pernyataan Zimmerman (1990: 7) yang menyatakan bahwa "Many times students have difficulty completing homework assignments becouse there are other, more interesting things they would rather do such as watching TV, daydreaming, or talking to friend". Secara jelas kita lihat banyak pelajar yang tidak menggunakan waktunya untuk menyelesaikan pekerjaan rumahnya dan belajar karena sibuk dengan banyak hal seperti menonton TV, main gadget, menghayal atau berbicang-bincang dengan temannya.

Kemudian Zimmerman dan Martinez-Ponz (dalam Yukselturk \& Bulut: 2009) menyatakan bahwa terdapat perbedaan penerapan self regulated learning antara siswa laki-laki dan juga perempuan, dimana siswa perempuan lebih sering menggunakan strategi monitor diri (self monitoring), membuat perencanaan dan tujuan belajar (goal 
setting \& planning), mengatur lingkungan belajar (environmental scructuring) dibandikngkan dengan laki-laki.

Dari penjelasan dan fenomena yang ada maka penelitian ini akan mencoba mencari tau bagaimana tingkat self regulated learning (SRL) yang dimiliki oleh mahasiswa STKIP Muhammadiyah Sungai Penuh dan mengetahui bagaimana mebandingkan SRL yang diiliki oleh mahasiswa perempuan dan mahasiswa laki-laki.

Adapun tujuan penelitian yang hendak dicapai pada penelitian ini adalah Mendeskripsikan SRL mahasiswa STKIP Muhamadiyah Sungai Penuh baik itu laki-laki maupun perempuan. Kemudian penelitian ini juga bertujuan untuk menguji apakah terdapat perbedaan yang signifikan antara SRL mahasiswa laki-laki dan perempuan.

\section{METODE PENELITIAN}

Penelitian ini menggunakan metode kuantitatif jenis deskriptif untuk mendesripsikan keadaan SRL mahasiswa STKIP Muhammadiyah secara keseluruhan dan deskriptif komparatif untuk membandingkan SRL mahasiswa laki-laki dan perempuan di STKIP Muhammadiyah Sungai penuh.

Populasi penelitian ini adalah mahasiswa STKIP Muhammadiyah Sunga Penuh pada prodi Pendidikan Matematika, pendidikan Fisika, Bimbingan dan konseling, pendidikan Bahasa Indonesia, pendidikan Bahasa Inggris dan pendidikan Olah Raga pada tahun ajaran 2017/2018 yang berjumlah 991 orang, dan sampel berjumlah 276 orang, yang dipilih dengan stratified random sampling. Instrumen yang digunakan adalah skala dengan reliabilitas 0,995 (SRL). Data dianalisis dengan rumus presentase dan rumus Komparatif yaitu t-test.

\section{HASIL PENELITIAN}

\section{Deskripsi Data}

Data dalam penelitian ini meliputi data SRL mahasiswa STKIP Muhammadiyah Sungai Penuh secara keseluruhan dan juga data SRL mahasiswa laki-laki dan mahasiswa perempuan secara terpisah.

\section{SRL Mahasiswa Laki-laki dan Perempuan di STKIP Muhammadiyah Sungai Penuh}

Deskripsi data SRL mahasiswa Laki-laki STKIP Muhammadiyah Sungai Penuh yang berjumlah 120 responden laki-laki dan 156 responden perempuan dapat dilihat pada tabel 1 . 
Tabel 1. Hasil pengolahan data SRL Laki-laki dan perempuan di STKIP Muhammadiyah Sungai Penuh

\begin{tabular}{|c|c|c|c|c|c|}
\hline \multirow{3}{*}{$\begin{array}{l}\text { Interval } \\
\text { Skor }\end{array}$} & \multirow{3}{*}{ Kategori } & \multirow{2}{*}{\multicolumn{2}{|c|}{$\begin{array}{c}\text { Laki-laki } \\
\text { Total }\end{array}$}} & \multirow{2}{*}{\multicolumn{2}{|c|}{$\begin{array}{c}\text { Perempuan } \\
\text { Total }\end{array}$}} \\
\hline & & & & & \\
\hline & & $\mathbf{F}$ & $\%$ & $\mathbf{F}$ & $\%$ \\
\hline$\geq 214$ & $\begin{array}{l}\text { Sangat Baik } \\
\text { (SB) }\end{array}$ & 12 & 10 & 31 & 19,87 \\
\hline $173-213$ & Baik (B) & 33 & 27,5 & 43 & 27,56 \\
\hline $132-172$ & $\begin{array}{l}\text { Cukup Baik } \\
\text { (CB) }\end{array}$ & 16 & 13,3 & 37 & 23,71 \\
\hline $91-131$ & $\begin{array}{l}\text { Kurang Baik } \\
\text { (KB) }\end{array}$ & 39 & 32,5 & 20 & 12,82 \\
\hline$\leq 90$ & Tidak Baik (TH & 20 & 16,6 & 25 & 16,02 \\
\hline & Total & 120 & 100 & 156 & 100 \\
\hline
\end{tabular}

Berdasarkan Tabel 1 dapat dilihat bahwa mahasiswa laki-laki memiliki SRL yang beragam, setengah dari mahasiswa memiliki SRL yang baik dan sebagian lagi memiliki SRL yang kurang baik. Hal ini berbeda dengan mahasiswa perempuan yang lebih dari 50\% yaitu sebanyak 52\% mahasiswa memiliki SRL yang baik dan cukup baik. Jadi, dapat disimpulkan bahwa secara keseluruhan rata-rata SRL mahasiswa laki-laki dan perempuan di STKIP Muhammadiyah memiliki SRL yang baik dan sebagian lagi masih tergolong kurang baik.

\section{SRL Mahasiswa STKIP Muhammadiyah Sungai Penuh Secara Keseluruhan}

Bila dilihat secara keseluruhan, maka SRL mahasiswa STKIP muhammadiyah sungai penuh dapat dilihat pada tabel 2 beriut ini.

Tabel 2. Hasil pengolahan data SRL Mahasiswa STKIP Muhammadiyah Sungai Penuh

\begin{tabular}{|c|c|c|c|}
\hline \multirow{2}{*}{$\begin{array}{l}\text { Interval } \\
\text { Skor }\end{array}$} & \multirow[t]{2}{*}{ Kategori } & \multicolumn{2}{|c|}{ Total } \\
\hline & & $\mathbf{F}$ & $\%$ \\
\hline$\geq 214$ & Sangat Baik (SB) & 43 & 15,5 \\
\hline $173-213$ & Baik (B) & 76 & 27,5 \\
\hline $132-172$ & Cukup Baik (CB) & 53 & 19,2 \\
\hline $91-131$ & Kurang Baik (KB) & 59 & 21,3 \\
\hline$\leq 90$ & Tidak Baik (TB) & 45 & 16,3 \\
\hline & Total & 276 & 100 \\
\hline
\end{tabular}


Dari tabel 2 dapat diketahui bahwa SRL mahasiswa STKIP Muhammadiyah Sungai Penuh memiliki frekuensi yang menyebar, yang paling banyak adalah berkategori Baik (27,5\%) dan disusul dengan kategori kurang baik yaitu 21,3\%. Dari hal tersebut dapat diketahui bahwa setengah dari mahasiswa memiliki SRL yang baik an setangahnya lagi memiliki SRL yang kurang baik.

\section{Uji Hipotesis}

Dalam penelitian ini terdapat hipotesi yang diuji kebenarannya. Berikut merupakan paparan hasil uj hipotesis penelitian, yang dapat dilihat pada tabel 3 berikut ini.

Tabel 3. Hasil Uji Hipotesis

\begin{tabular}{|c|c|c|c|c|c|c|c|c|}
\hline Variabel & Budaya & N & Mean & Dk & MS & $F_{\text {hitung }}$ & Sig. & Ket. \\
\hline \multirow{2}{*}{ SRL } & Laki-laki & 120 & 182,25 & \multirow{2}{*}{1} & 3091,21 & 5,25 & 0,023 & Signifikan \\
\cline { 2 - 5 } & Perempuan & 156 & 190,67 & & & & & \\
\hline
\end{tabular}

Dari tabel 3 di atas, dapat diketahui bahawa hasil ui hipotesis menunjukkan bahwa terdapat perbedaan yang signifikan antara SRL mahasiswa laki-laki dan perempuan

di STKIP Muhammadiyah Sungai Penuh. Dimana SRL perempuan lebih baikdibandingkan dengan SRL laki-laki. Artinya bahwa Hipotesis diterima.

\section{PEMBAHASAN}

Berdasarkan hasil penelitian diperoleh data bahwa SRL mahasiswa laki-laki dan perempuan di STKIP Muhammadiyah memiliki perbedaan yang signifikan. Dimana SRL mahasiswa perempuan lebih baik dibandingkan dengan SRL yang dimiliki oleh mahasiswa laki-laki. Hal ini berarti bahwa temuan penelitian sesuai dengan hipotesis penelitian yang diajukan sebelumnya.

Hasil penelitian ini sesuai dengan pernyataan Zimmerman dan Martinez-Ponz (dalam Yukselturk \& Bulut: 2009) menyatakan bahwa terdapat perbedaan penerapan self regulated learning antara siswa laki-laki dan juga perempuan, dimana siswa perempuan lebih sering menggunakan strategi monitor diri (self monitoring), membuat perencanaan dan tujuan belajar (goal setting \& planning), mengatur lingkungan belajar (environmental scructuring) dibandikngkan dengan laki-laki.

Kemudian hasil penelitian yang di peroleh juga didukung oleh hasil penelitian sebelumnya yaitu Hasil penelitian Lien, Tilor, Seeeman (2001) di California menunjukkan bahwa bahwa "on the self regulation questionaires, women showed a more 
positive attitude thinking about the past and had higher expectancies for future goal achievment that did men". Artinya bahwa self regulated learing perempuan lebih positif dibandingkan dengan laki-laki. Namun terdapat juga hasil penelitian yang menjelaskan bahwa laki-laki memiliki SRL yang lebih baik dibandingkan dengan perempuan yaitu penelitian yang dilakukan oleh Jenni Kurma pada tahun 2001 yang melakukan penelitian di Israel dan singapura.

Adanya perbedaan SRL yang dimiliki oleh laki-laki dan perempuan juga di sebabkan oleh banyak faktor. Faktor tersebut yaitu faktor dari individu itu sendiri, faktor perilaku, dan juga faktor lingkungan. Zimmerman (dalam Subran, 2001:13) merancang sebuah formulasi self regulated learning berdasarkan pada teori triandik Bandura yaitu teori sosial cognitif, dimana keberadaan self regulated learning dipengaruhi oleh tiga wilayah yakni wilayah individu, wilayah perilaku dan wilayah lingkungan yang memiliki hubungan yang timbal balik antara ketiganya. Berikut adalah model self regulated learning berdasarkan perspectif teori sosial kognitif.

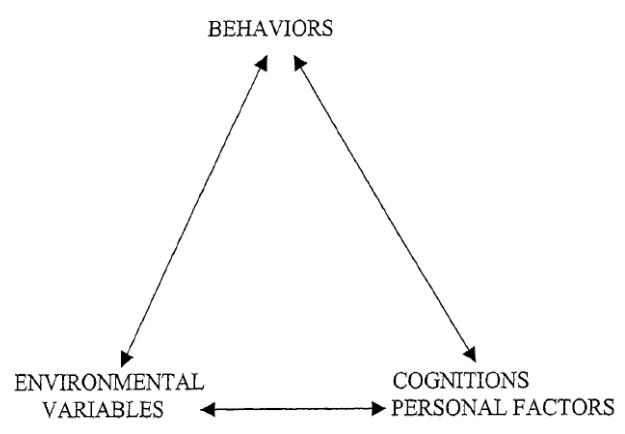

Gambar 1

\section{Social cognitive model of SRL}

Kemudian, bila dikaitkan dengan budaya perbedaan SRL antara laki-laki dan perempuan dapat dikaitkan dengan perbedaan peran gender pada sebuah budaya tentu akan mempengaruhi SRL laki-laki dan perempuan. Secara umum Crandall, Maccoby \& Jacklin (dalam Jenny Kerma, 2001) menyatakan bahwa "general traditional gender differences show that women have lower expectancies of success that men in achievement area", artinya bahwa perbedaan jenis kelamin menunjukkan perbedaan keinginan untuk sukses, dimana perempuan memiliki ekspektasi untuk sukses yang lebih rendah dibandingkan dengan laki-laki. Dalam hal ini ekspektasi seseorang untuk sukses akan mempengaruhi self regulated learningnya. Namun hal tersebut bisa saja berbeda 
pada tiap budaya, karena berbeda budaya akan berbeda pula tingkat keinginan untuk sukses pada laki-laki dan perempuan.

Menurut Winne (1997) pelajar atau mahasiswa yang memiliki SRL yang baik berarti siswa telah mampu untuk mengelola proses belajarnya secara efektif dengan menggunakan berbagai cara yang positif, sehingga siswa mampu untuk mencapai hasil belajar yang optimal dan sesuai dengan yang telah ditargetkan sebelumnya. Mahasiswa perempuan artinya lebih mampu mengelola proses belajarnya baik dirumah, di kampus ataupun diperpustakaan.

Seperti yang kita ketahui bahwa mahasiswa sebagai manusia yang berada pada usia yang telah dianggap mampu mengatur dirinya sendiri, dituntut untuk mampu mengatur pembelajarannya sendiri. Menurut Prayitno, dkk (2002:10) dalam sistem kredit semester ini ada tiga bentuk kegiatan yang harus dilakukan mahasiswa yaitu, 1) mengikuti perkuliahan tatap muka terjadwal yang berlangsung 16-17 kali pertemuan dalam satu semester, 2) mengerjakan tugas-tugas yang diberikan oleh dosen, dan 3) kegiatan belajar mandiri. Dari penjelasan tersebut dapat dioahami bahwa cara belajar mahasiswa sangat berbeda dengan siswa, dimana mahasiswa dituntut untuk bisa belajar mandiri.

Selain itu sistem belajar di perguruan tinggi yang menggunakan sistem SKS (sistem kredit semester) juga menuntut mahasiswa mampu mengatur belajarnya sendiri agar bisa memperoleh nilai atau hasil belajar yang memuaskan. Namun hasil penelitian yang menunjukkan masih banyaknya mahasiwa STKIP Muhammadiyah yang memiliki SRL yang kurang baik, hal ini juga terlihat dari jumlah mahasiswa yang memiliki nilai BL (belum lengkap) dalam satu semester cukup banyak. Data yang di peroleh dari bagian TU di STKIP Muhammadiyah sungai penuh, pada semester ganjil tahun ajaran 2017/2018 masih ada sekitar 25\% dari seluruh mahasiswa di STKIP Muhammadiyah sungai penuh yang memiliki nilai BL (belum lengkap). Dari hal tersebut dapat dihubungkan dengan hasil penelitian yang diperoleh peneliti.

\section{KESIMPULAN}

Berdasarkan temuan dan pembahasan hasil penelitian, dapat dikemukakan kesimpulan sebagai berikut.

1. SRL mahasiswa laki-laki di STKIP Muhammadiyah sungai penuh sebagian besar $(32,5 \%)$ tergolong kurang baik, dan sebagian lagi $(27,5 \%)$ tergolong Baik. 
2. SRL mahasiswa perempuan di STKIP Muhammadiyah sungai penuh sebagian besar tergolong baik $(27,56 \%)$ dan cukup baik $(23,71 \%)$.

3. Secara keseluruhan SRL mahasiswa STKIP Muhammadiyah Sungai penuh terbagi menjadi dua golongan yaitu baik $(27,5 \%)$ dan kurang baik $(21,3 \%)$.

4. Hipotesis yang diuji dalam penelitian ini terbukti, bahawa terdapat perbedaan SRL yang signifikan antara mahasiswa laki-laki dan perempuan, di STKIP Muhammadiyah sungai penuh, dimana perempuan memiliki SRL yang lebih baik di bandingkan dengan laki-laki.

\section{SARAN}

SRL merupakan sebuah pola belajar yang dibangun dari anak berusia dini hingga ia dewasa, artinya SRL ini akan dipengeruhi oleh bagaimana orang tua melatihnya sejak dini. Oleh karna itu orang tua sangat disarankan melakukan pembiasaan pada anak untuk mengatur dirinya sendiri termasuk mengatur diri sendiri dalam belajar. Anak yan telah dibiasakan untuk mengatur dirinya sendiri maka ia akan lebih mudah mencapai prestasi belajarnya ketika ia dewasa kelak.

Kemudian diperguruan tinggi hendaknya diberikan orientasi awal dengan metode yang baik tentang sistem pekuliahan di perguruan tinggi kepada para mahasiswa barunya dengan melibatkan UPBK dalam pelaksanaannya. Tujuannya untuk memberikan pengenalan cara belajar yang seharusnya di terapkan di perguruan tinggi oleh seorang mahasiswa untuk dapat mencapai prestasi belar yang optimal.

Selain itu, hasil penelitian ini dapat dijadikan sebagai bahan pemikiran bagi pengelola kampus STKIP Muhammadiyah sungai penuh dalam upaya meningkatkan kualitas kepribadian mahasiswanya, misalnya dengan membentuk worshop ataupun pelatihan-pelatihan yang berguna untuk meningkatkan kemandirian dan SRL yang dimiliki oleh siswa. 


\section{DAFTAR RUJUKAN}

Jenny, K. 2001. "Self Regulated Strategies in Achievement Settings Cullture and Gender Differences". Universitas of Haifa. Journal of Cross Cultural Phychology. 32 (4): 491-503.

Lien, B.P., Tilor, E., \& Seeman, T.E. 2001. Effects of Environmental Predictability and Personal Mastery on Self Regulatory and Physiological Processes. California: The Society For Personality and Social Psychology.

Paul, R. P., Elisabeth, A. M., \& Robert, W. R. 1994. "Classroom and Individual Diferences in Early Adolescets Motivation dan Self Regulated Learning”. Jurnal of Early Adolescence. 14 (2): 139-161.

Prayitno \& Amti, E. 2004. Dasar-dasar Bimbingan Konseling. Cetakan Kedua. Jakarta: Rineka Cipta.

Prayitno. 2009. Dasar Teori dan Praktis Pendidikan. Jakarta: Gramedia.

Schunk, H. D. 2005. Self regulated learning: The educational legacy of Paul R. Pintrich. Educational Psychologist, 40 (2): 85-94.

Subran, A. A. 2001. "Self Regulated Learning and Acade mic Achievement of Hongkong and Indian High School Students". Disertasi. University of Hong Kongkong.

Winne, P. H. 1997. "Experimenting to Bootstrap Self-Regulated Learning”. Journal of Educational Psychology, (Online). 3 (89): 397-410, (ftp://ftp.uwc.ac.za/users/DMS/CITI/bootstrapping.pdf/, diakses 04 April 2015).

Yukkselturk, E., \& Bulut, S. 2009. "Gender Differences in Self Regulated Learning Online Learning Environmental”. Educational Tecnology dan Society, 12-22 (Online). Available FTP: http://www.infets.info/ journals/12-3/3.pdf tanggal akses 10 maret 2015 .

Zimmerman \& Pons. 1990. "Student Differences in Self Regulated Learning: Relating grade, sex, and giftedness to self eficacy and strategy use". Journal of Educational Psychology. 82(1): 51-59.

Zimmerman. 1989. “A Social Cognitive View of Self Regulated Learning”. Journal of Educational Psychology. 81 (3): 329-339.

Zimmerman. 1990. "Self Regulated Learning adn Academic Achievement: An overview". Journal of Educational Psychologist. 25 (1): 3-17.

Zimmerman. 2002. "Becoming a Self Regulated Learner: An overview". Theory Into Practice. 41 (2) : 64-70. 